\title{
Article \\ NTBC Treatment Monitoring in Chilean Patients with Tyrosinemia Type 1 and Its Association with Biochemical Parameters and Liver Biomarkers
}

\author{
Karen Fuenzalida *, María Jesús Leal-Witt *, Patricio Guerrero, Valerie Hamilton, María Florencia Salazar, \\ Felipe Peñaloza, Carolina Arias and Verónica Cornejo $\mathbb{D}$
}

check for updates

Citation: Fuenzalida, K.; Leal-Witt M.J.; Guerrero, P.; Hamilton, V.; Salazar, M.F.; Peñaloza, F.; Arias, C.; Cornejo, V. NTBC Treatment Monitoring in Chilean Patients with Tyrosinemia Type 1 and Its Association with Biochemical Parameters and Liver Biomarkers. J. Clin. Med. 2021, 10, 5832. https:// doi.org/10.3390/jcm10245832

Academic Editors:

Luis Peña-Quintana,

Domingo González-Lamuño and John Griffith Jones

Received: 10 September 2021

Accepted: 8 December 2021

Published: 13 December 2021

Publisher's Note: MDPI stays neutral with regard to jurisdictional claims in published maps and institutional affiliations.

Copyright: (c) 2021 by the authors. Licensee MDPI, Basel, Switzerland. This article is an open access article distributed under the terms and conditions of the Creative Commons Attribution (CC BY) license (https:// creativecommons.org/licenses/by/ $4.0 /)$.
Instituto de Nutrición y Tecnología de Alimentos INTA, Universidad de Chile, Santiago 7830490, Chile; patricio.guerrero@inta.uchile.cl (P.G.); vhamilton@inta.uchile.cl (V.H.); mfsalazar@inta.uchile.cl (M.F.S.); felipe.penaloza@inta.uchile.cl (F.P.); carias@inta.uchile.cl (C.A.); vcornejo@inta.uchile.cl (V.C.)

* Correspondence: kfuenzalida@inta.uchile.cl (K.F.); mj.leal@inta.uchile.cl (M.J.L.-W.)

\begin{abstract}
Treatment and follow-up in Hereditary Tyrosinemia type 1 (HT-1) patients require comprehensive clinical and dietary management, which involves drug therapy with NTBC and the laboratory monitoring of parameters, including NTBC levels, succinylacetone (SA), amino acids, and various biomarkers of liver and kidney function. Good adherence to treatment and optimal adjustment of the NTBC dose, according to clinical manifestations and laboratory parameters, can prevent severe liver complications such as hepatocarcinogenesis (HCC). We analyzed several laboratory parameters for 15 HT-1 patients over one year of follow-up in a cohort that included long-term NTBC-treated patients (more than 20 years), as well as short-term patients (one year). Based on this analysis, we described the overall adherence by our cohort of $70 \%$ adherence to drug and dietary treatment. A positive correlation was found between blood and plasma NTBC concentration with a conversion factor of 2.57. Nonetheless, there was no correlation of the NTBC level with SA levels, $\alpha$ FP, liver biomarkers, and amino acids in paired samples analysis. By separating according to the range of the NTBC concentration, we therefore determined the mean concentration of each biochemical marker, for NTBC ranges above 15-25 $\mathrm{mol} / \mathrm{L}$. SA in urine and $\alpha \mathrm{FP}$ showed mean levels within controlled parameters in our group of patients. Future studies analyzing a longer follow-up period, as well as SA determination in the blood, are encouraged to confirm the present findings.
\end{abstract}

Keywords: tyrosinemia type-1; nitisinone; succinylacetone; alpha fetoprotein; liver biomarkers

\section{Introduction}

Hereditary tyrosinemia type-1 (HT-1) is an autosomal recessive inborn error of metabolism caused by a deficiency in the enzyme fumarylacetoacetate hydrolase (FAH), which affects the degradation pathway for tyrosine (Tyr) and leads to insufficiency in glucogenic metabolites. Globally, the prevalence of this condition is 1 per 100,000 newborns, but it has been shown to be higher in some regions-specifically, Quebec, Canada, where its prevalence is $1: 1846[1,2]$.

As a result of FAH dysfunction, the conversion of fumarylacetoacetate to fumarate, acetoacetate, and succinate is impaired. Accumulated 4-maleylacetoacetate and 4-fumarylacetoacetate are then reduced to succinylacetoacetate, which, in turn, is decarboxylated to succinylacetone (SA), the pathognomic biomarker of HT-1 [3]. Increased SA levels are found in biological fluids in affected newborns, and chronic elevation of these metabolites leads to the development of hepatocellular carcinoma (HCC), renal tubulopathy, glomerular disease, heart disease, and neurological problems [3,4]. Early diagnosis is crucial to promptly initiate pharmacological treatment and prevent the onset of critical complications. Treatment is based on the daily administration of 2-(2-nitro-4-trifluoromethylbenzoyl)-1,3-cyclohexanedione (NTBC), a herbicide that strongly inhibits the enzymatic activity of 4-hydroxy-phenylpyruvic dioxygenase (4HPPD), the 
second enzyme in the catabolic pathway of Tyr [5]. Once NTBC treatment is initiated, excretion of SA is hampered, and the levels of alpha-fetoprotein $(\alpha \mathrm{FP})$ - the liver biomarker of HCC progression-decrease slowly over a few months, until they reach normal values [6-8]. As the blockage caused by NTBC is in proximity to the first steps of the Tyr degradation cascade, Tyr levels increase, causing ocular problems and thrombocytopenia. To reverse these secondary complications and maintain good metabolic control, dietary restriction of phenylalanine (Phe) and Tyr is essential, in combination with NTBC treatment [9].

In Chile, 19 patients with HT-1 are under active follow-up on NTBC treatment, a Phe/Tyr restricted diet, and a Tyr-free/low-Phe protein substitute (PS) supplement. As is the case in many low- and middle-income countries, HT-1 is not included in our National Neonatal Screening Program, which only considers detection by heel stick at $40 \mathrm{~h}$ post-birth of Phenylketonuria and Congenital Hypothyroidism. Consequently, most of our patients were diagnosed by clinical presentation at different ages. Only one, who had a family history (siblings), was diagnosed in the neonatal period. Favorably, HT-1 patients have access to the government's Financial Protection for High-Cost Diagnoses and Treatments System (Law No. 20850, 2015), which guarantees lifetime access to subsidized NTBC treatment and Tyr-free/low-Phe PS. Clinical, dietary, psychological, and biochemical monitoring has been carried out quarterly at our center from 1996, which is designated as the national reference center for diagnosis and follow-up of HT-1 and other IEM pathologies.

Management of HT-1 patients follows current consensus guidelines, and since 2018, our laboratory has monitored NTBC concentrations through liquid chromatography-mass spectrometry (LC-MS) in whole blood and plasma. Additionally, urinary SA levels and plasma amino acids are also routinely screened using the same methodology. NTBC dosage, dosing regimen, and the optimal therapeutic values of NTBC in the blood and plasma for management have emerged as questions in recent years [10-13]. A divided dose of NTBC has been shown to increase NTBC concentrations in the blood, compared to a once-a-day dosing system [10]. Moreover, the target range of NTBC in dried blood spot (DBS) samples needed to keep SA values at a minimum appears to be lower than the recommendation in the current consensus guidelines, as has been indicated in recently published studies $[11,14]$.

This study aimed to associate the NTBC concentration in blood with SA levels, $\alpha$ FP, biochemical parameters, and liver biomarkers, while describing the overall adherence of our patients over one year of follow-up (2019-2020).

\section{Materials and Methods}

This was a retrospective observational and cross-sectional study conducted in the years 2019-2020. Fifteen HT-1 patients were included from the total of nineteen patients in active follow-up during 2019. The four patients not included in the study had been diagnosed less than a year before the study began. The clinical records of the patients between April 2019 and January 2020 provided follow-up data for one year, during which data were collected every three months (2019: April, July, October; 2020: January), as per our protocol for regular outpatient clinical visits. Following the national protocol published by the Chilean Ministry of Health [13], the entire cohort was treated as follows: NTBC recommended dose, $1 \mathrm{mg} / \mathrm{kg}$ /day (twice daily); protein restricted to $0.5 \mathrm{~g} / \mathrm{kg} /$ day, supplemented with Tyr-free/low-Phe PS to $1.5-3.0 \mathrm{~g} / \mathrm{kg} /$ day, considering an additional $20 \%$ to account for PS bioavailability. Infants received $400-500 \mathrm{mg} /$ day, increasing in toddlers, adolescents, and adults up to $900 \mathrm{mg} /$ day, depending on the Tyr and Phe plasma profile.

\subsection{Material and Reagents}

NTBC, Mesotriene, succinylacetone, and the amino acid mix were purchased from Sigma-Aldrich (Saint Louis, MO, USA) at the highest purity grade available. Internal standards were obtained from Cambridge Isotope Laboratories (Tewksbury, MA, USA., Amino acid Mix MSK-CAA-1, Labeled SU NSK-T-1). HPLC-grade solvents (methanol, acetonitrile, and water) were purchased from Merck (Saint Louis, MO, USA). Other chem- 
ical reagents, including hydrazine, formic acid (FA), and acidic butanol, were obtained from Sigma-Aldrich (Saint Louis, MO, USA). The following chromatographic columns were purchased from GLScience (Torrance, CA, USA): Symmetry C8 $5 \mu \mathrm{m} \times 4.6 \times 150 \mathrm{~mm}$ from Waters Company ${ }^{\mathrm{TM}}$ (Milford, MA, USA) and InertSustain C18 $2 \mu \mathrm{m} \times 2.1 \times 50 \mathrm{~mm}$ (Hampshire, SO51BJJ, UK).

\subsection{Clinical Samples}

DBS, plasma, and urine samples from 15 HT-1 patients were collected at each clinical visit to the center. A mean of 50 samples of each biological sample was analyzed in 2019 and 2020. For the correlation studies, paired samples from each patient at each medical check-up were analyzed as independent samples. For each biochemical parameter, the reference range for adequate adherence was DBS NTBC $20-40 \mu \mathrm{mol} / \mathrm{L}$, plasma NTBC 40-60 $\mu \mathrm{mol} / \mathrm{L}$, SA $<0.5 \mathrm{mmol} / \mathrm{mol}$ creatinine, Tyr 400-600 $\mu \mathrm{mol} / \mathrm{L}$, Phe $20-80 \mu \mathrm{mol} / \mathrm{L}$, and $\alpha \mathrm{FP}<10 \mu \mathrm{g} / \mathrm{L}$ [15]. The Institute of Nutrition and Food Technology (INTA) Ethics Committee granted ethical approval and approved patient-informed consent on 26 May 2021.

\subsection{Sample Preparation for NTBC, Succinylacetone, and Amino Acids}

For NTBC analysis in DBS, a $3.2 \mathrm{~mm}$-diameter disk from DBS was extracted with $255 \mu \mathrm{L}$ of methanol and $45 \mu \mathrm{L}$ of mesotriene $(10 \mu \mathrm{M})$. The mixture was shaken at room temperature for $60 \mathrm{~min}$ and then centrifuged at 11,750 $\mathrm{rcf}$ for $2 \mathrm{~min}$. The supernatant was transferred to a 96-well ELISA plate and injected into LC-MS/MS. For plasma NTBC quantification, $30 \mu \mathrm{L}$ of mesotriene $(10 \mu \mathrm{M})$ and $400 \mu \mathrm{L}$ of methanol were added to $50 \mu \mathrm{L}$ of plasma and incubated with agitation for $60 \mathrm{~min}$ at room temperature. After centrifugation, $300 \mu \mathrm{L}$ of the supernatant was transferred to a glass vial and evaporated to dryness under a stream of nitrogen. The sample was resuspended in $200 \mu \mathrm{L}$ of 60:40 methanol/water and $0.1 \%$ formic acid and then injected into the liquid chromatography-tandem mass spectrometer (LC-MS/MS). An NTBC calibration curve and internal control were extracted and analyzed in the same run as each patient's sample. The calibration curve corresponded to NTBC-spiked blood from a non-HT-1 affected subject $(0 \mu \mathrm{M}, 0.5 \mu \mathrm{M}, 5 \mu \mathrm{M}, 50 \mu \mathrm{M}$, and $100 \mu \mathrm{M})$.

For the SA preparation, $100 \mu \mathrm{L}$ of filtered urine was extracted by adding $100 \mu \mathrm{L}$ of methanol, $5 \mu \mathrm{L}$ of SCA-C5 $(0.1 \mathrm{mM}), 20 \mu \mathrm{L}$ water, and $375 \mu \mathrm{L}$ hydrazine $3 \mathrm{mM}$ (in $60: 40$ methanol/water, $0.1 \% \mathrm{FA}$ ). The mixture was incubated at $60{ }^{\circ} \mathrm{C}$ for $40 \mathrm{~min}$ to allow for SA derivatization. Then, $5 \mu \mathrm{L}$ was injected into the LC-MS/MS system. Each run used an internal control and calibration curve corresponding to spiked urine from control subjects with increasing SA concentrations $(0 \mu \mathrm{M}, 0.5 \mu \mathrm{M}, 5 \mu \mathrm{M}, 50 \mu \mathrm{M}$, and $100 \mu \mathrm{M})$. Quantitative results for SA were normalized to the corresponding urinary creatinine value and are expressed as $\mathrm{mmol} \mathrm{SA} / \mathrm{mol}$ creatinine.

The amino acid sample was prepared by extracting $50 \mu \mathrm{L}$ of plasma with $425 \mu \mathrm{L}$ of methanol and adding $1.5 \mu \mathrm{L}$ of labeled amino acids (MSK-CAA-1). After 10 seconds of vortexing, the vial was centrifuged at 11,750 $\mathrm{rcf}$ for $4 \mathrm{~min}$. Then, $200 \mu \mathrm{L}$ of the supernatant was transferred to a glass vial and evaporated to dryness under a stream of nitrogen. Butylation was carried out by resuspending with $50 \mu \mathrm{L}$ of butanol- $\mathrm{HCl} 3 \mathrm{~N}$ and incubating at $65{ }^{\circ} \mathrm{C}$ for $7.5 \mathrm{~min}$. The sample was evaporated to dryness and resuspended in $300 \mu \mathrm{L}$ of ACN $20 \%$ and $0.1 \%$ FA and then injected into LC-MS/MS ( $1 \mu \mathrm{L})$. The AA quantification used a linear calibration curve for each amino acid.

\subsection{Instrumentation and Analysis by LC-MS/MS}

NTBC, SA, and amino acid (AA) determinations were performed using a Shimadzu UFLC system coupled with a SCIEX 3500 ESI-MS/MS detector. For AA quantification, the chromatographic system was equipped with a C8 column $(150 \mathrm{~mm} \times 4.6 \mathrm{~mm}, 5 \mu \mathrm{m})$, while for NBTC and SA, a C18 column $(50 \mathrm{~mm} \times 2.1 \mathrm{~mm} \times 2 \mu \mathrm{m})$ was used. The AAs were separated using an isocratic flow of $0.8 \mathrm{~mL} / \mathrm{min}$, with a mobile phase comprising $20 \%$ 
ACN and $0.1 \%$ FA kept at $40{ }^{\circ} \mathrm{C}$. The total run was 10.5 minutes, and the sample volume injection was $10 \mu \mathrm{L}$. The MS/MS detector was adjusted to positive electrospray ionization at a temperature of $550{ }^{\circ} \mathrm{C}$ and source voltage of $3500 \mathrm{~V}$. The ESI-MS/MS parameter was optimized for each butylated AA and its corresponding labeled standard. The analyte concentration was determined with multiple reaction monitoring (MRM) mode in order to measure the peak areas of each AA's transition in relation to the respective internal standard peak area with a known concentration, using the MultiQuant ${ }^{\mathrm{TM}} 3.0 .2$ software. For chromatographic separation of NTBC and SA, a gradient of water/FA $0.1 \%$ (solvent A) and methanol/FA $0.1 \%$ (solvent B) was used. The total run was $6 \mathrm{~min}$, the volume of sample injection for SA was $5 \mu \mathrm{L}$, and that for plasma NTBC was $1 \mu \mathrm{L}$. MS/MS detection of each analyte was through MRM in positive electrospray ionization mode. The quantifier and qualifier transitions for NTBC were 330/218 and 330/125, respectively. Furthermore, for mesotriene, it was 340/228; SA, 155/137; and SA-C5, 160/142.

Accuracy for each LC-MS/MS-based analyte determination (except plasma NTBC) was determined by analyzing external proficiency testing samples from ERNDIM (European Research Network to Evaluate and Improve Screening, Diagnosis, and Treatment of Inherited Disorders of Metabolism). The limits of quantification were as follows: SA, $0.1 \mu \mathrm{mol} / \mathrm{L} ; \mathrm{AA}, 2 \mu \mathrm{mol} / \mathrm{L}$; and NTBC, $0.5 \mu \mathrm{mol} / \mathrm{L}$.

\subsection{Alpha-Fetoprotein and Liver Biomarker Determination}

For HT-1 patient blood analysis of liver function, alanine transaminase (ALT), aspartate transaminase (AST), gamma-glutamyl transaminase (GGT), prothrombin time (PT), INR, bilirubin total and direct, alkaline phosphatase, and alpha-fetoprotein $(\alpha \mathrm{FP})$ were determined quarterly in the Central Laboratory at Dr. Calvo Mackenna Hospital (CMH) in Santiago, Chile. Under the Chilean program of diagnosis and follow-up of HT-1 patients, $\mathrm{CMH}$ and its clinical gastroenterology team collaborate on follow-up and are the designated referral center for hepatic transplantation.

\subsection{Statistical Analysis}

A descriptive analysis of the variables, including all the independent variables, was conducted using the GraphPad Prism 8.4.0 software (San Diego, CA, USA). For each variable, the distribution was determined using the Shapiro-Wilk test. To compare samples, we used the Wilcoxon test, and Spearman's correlation was used to verify the associations between variables.

\section{Results}

Fifteen HT-1 patients in active follow-up were enrolled in the study. The mean age of patients at the time of last analysis was 11 years, 4 months (range: 1 year, 3 months to 23 years, 4 months). Two patients had less than 5 years of follow-up, and 13 patients had more than 5 years of follow-up, with a maximum of 23 years. Sixty-six percent of patients were female. Because, in Chile, there is no NBS for HT-1, 14 of the 15 patients were diagnosed by clinical manifestation; the other was diagnosed as a result of sibling diagnosis 25 days after birth. Median age at diagnosis was 7 months (range: 25 days to 3 years, 11 months). First, biological samples taken over one year at quarterly clinical and biochemical controls were analyzed as a single group in order to assess the general metabolic status of our HT-1 patients. Table 1 shows the median, mean, minimum, and maximum values for each parameter. The mean NTBC administered in a twice-daily regimen for all patients was $0.95 \mathrm{mg} / \mathrm{kg} /$ day. Pharmacological adherence to treatment was determined by measuring NTBC levels in the plasma and DBS. For plasma and DBS samples, $48 \%$ and $33 \%$ of samples were within recommended reference values [16], with means of $50.4 \mu \mathrm{mol} / \mathrm{L}$ and $23.6 \mu \mathrm{mol} / \mathrm{L}$, respectively. Associating the effect of NTBC with SA excretion in urine, we found that more than $89 \%$ of analyzed samples presented levels below $0.5 \mathrm{mmol} / \mathrm{mol}$ of creatinine, even though $30 \%$ of analyzed samples showed lower-than-recommended NTBC levels in plasma $(<40 \mu \mathrm{mol} / \mathrm{L})$. Dietary adherence during 
the period was determined by comparing the Tyr and Phe levels with the reference range described in the management protocol, under which the Tyr and Phe levels should be kept between 400 and $600 \mu \mathrm{mol} / \mathrm{L}$ and 20 and $80 \mu \mathrm{mol} / \mathrm{L}$, respectively. We observed that $67 \%$ of the analyzed samples were within the recommended Tyr range, with an average value of $584.2 \mu \mathrm{mol} / \mathrm{L}$ (range: 319.4-1181.6), and 83\% were within the recommended Phe range (mean: $47.8 \mu \mathrm{mol} / \mathrm{L}$; range: $18.1-76.7$ ). It is worth noting that $60 \%$ of patients with HT-1 were on Phe supplementation.

Table 1. Laboratory follow-up parameters for Chilean patients with HT-1.

\begin{tabular}{|c|c|c|c|c|}
\hline Parameter & Analysis & Value & Samples $(n)$ & $\begin{array}{c}\text { Recommended } \\
\text { Reference Value * }\end{array}$ \\
\hline NTBC doses (mg/kg/day) & $\begin{array}{c}\text { Median } \\
\text { Mean } \pm \text { SD } \\
\text { Min-max }\end{array}$ & $\begin{array}{c}0.97 \\
0.95 \pm 0.17 \\
0.66-1.31\end{array}$ & 57 & $1.0 \mathrm{mg} / \mathrm{kg} /$ day \\
\hline NTBC concentration ( $\mu \mathrm{mol} / \mathrm{L}) \mathrm{DBS}$ & $\begin{array}{c}\text { Median } \\
\text { Mean } \pm \text { SD } \\
\text { Min-max }\end{array}$ & $\begin{array}{c}21.3 \\
23.6 \pm 12.6 \\
3.46-60.14\end{array}$ & 57 & $20-40 \mu \mathrm{mol} / \mathrm{L}$ \\
\hline NTBC concentration ( $\mu \mathrm{mol} / \mathrm{L})$ Plasma & $\begin{array}{c}\text { Median } \\
\text { Mean } \pm \text { SD } \\
\text { Min-max }\end{array}$ & $\begin{array}{c}50.6 \\
50.4 \pm 21.8 \\
9.8-101.6\end{array}$ & 43 & $40-60 \mu \mathrm{mol} / \mathrm{L}$ \\
\hline Tyrosine plasma $(\mu \mathrm{mol} / \mathrm{L})$ & $\begin{array}{c}\text { Median } \\
\text { Mean } \pm \text { SD } \\
\text { Min-max }\end{array}$ & $\begin{array}{c}460.7 \\
584.2 \pm 253.4 \\
319.4-1181.6\end{array}$ & 58 & $400-600 \mu \mathrm{mol} / \mathrm{L}$ \\
\hline Phenylalanine plasma ( $\mu \mathrm{mol} / \mathrm{L})$ & $\begin{array}{c}\text { Median } \\
\text { Mean } \pm \text { SD } \\
\text { Min-max }\end{array}$ & $\begin{array}{c}47.4 \\
47.8 \pm 19.5 \\
18.05-76.7\end{array}$ & 58 & $20-80 \mu \mathrm{mol} / \mathrm{L}$ \\
\hline Methionine plasma $(\mu \mathrm{mol} / \mathrm{L})$ & $\begin{array}{c}\text { Median } \\
\text { Mean } \pm \text { SD } \\
\text { Min-max }\end{array}$ & $\begin{array}{c}23.83 \\
25.18 \pm 6.4 \\
16.5-40.5\end{array}$ & 58 & $14-43 \mu \mathrm{mol} / \mathrm{L}$ \\
\hline Succinylacetone (mmol/mol creatinine) & $\begin{array}{l}<0.5 \\
>0.5\end{array}$ & $\begin{array}{l}89 \% \\
11 \%\end{array}$ & 53 & $\begin{array}{c}<0.5 \mathrm{mmol} / \mathrm{mol} \\
\text { creatinine }\end{array}$ \\
\hline
\end{tabular}

* According to consensus guidelines: Chinsky et al., 2017 [16]; Van Sprosen, 2017 [9].

\subsection{Comparison of NTBC Concentration in Plasma and DBS}

To date, few studies have addressed whether the NTBC concentrations measured in plasma and DBS are correlated, and whether the conversion factor is equivalent in different HT-1 patient cohorts [17-19]. In a paired study of 43 plasma and DBS samples, we identified the correlation coefficient for NTBC concentrations between the two types of samples. We found a significant correlation between NTBC levels measured in DBS and plasma (Spearman r: 0.8046; $p<0.0001$ ), with a conversion factor of 2.57 (Figure 1), which we can use to transform NTBC values from DBS into plasma values. Given our determination of equivalence between the two types of samples, and considering the most accepted range for NTBC levels in plasma samples $(40-60 \mu \mathrm{mol} / \mathrm{L})$, the calculated range for NTBC in DBS would be 15-24.5 $\mu \mathrm{mol} / \mathrm{L}(38.6-64 \mu \mathrm{mol} / \mathrm{L}$ in plasma).

\subsection{Association of Succinylacetone Excretion in Urine with NTBC Concentration}

Table 2 shows the mean and median NTBC concentrations for both plasma and DBS in a set of samples grouped according to SA excretion levels found in urine samples taken at the same time as the plasma and DBS. The first cut-off value (COV) was $0.25 \mathrm{mmol} / \mathrm{mol}$ creatinine; we established a second at $0.5 \mathrm{mmol} / \mathrm{mol}$ creatinine to evaluate whether significant differences in mean NTBC could be found, in relation to the SA excretion level. Nearly $80 \%$ of the analyzed urine samples presented SA values below $0.25 \mathrm{mmol} / \mathrm{mol}$ creatinine. When the recommended limit was raised to $0.5 \mathrm{mmol} / \mathrm{mol}$ creatinine, the 
percentage increased to $89.7 \%$. In both sets of samples, slight or no significant differences were found in mean NTBC concentration, whether detected in plasma or DBS, with SA limits at 0.25 and $0.5 \mathrm{mmol} / \mathrm{mol}$ creatinine. The mean NTBC concentration in DBS was 22.9 and $23 \mu \mathrm{mol} / \mathrm{L}$ in samples with SA below 0.25 and $0.5 \mathrm{mmol} / \mathrm{mol}$ creatinine, respectively, and 14.4 and $15.5 \mu \mathrm{mol} / \mathrm{L}$, respectively, in samples with SA levels higher than the above mentioned COV.

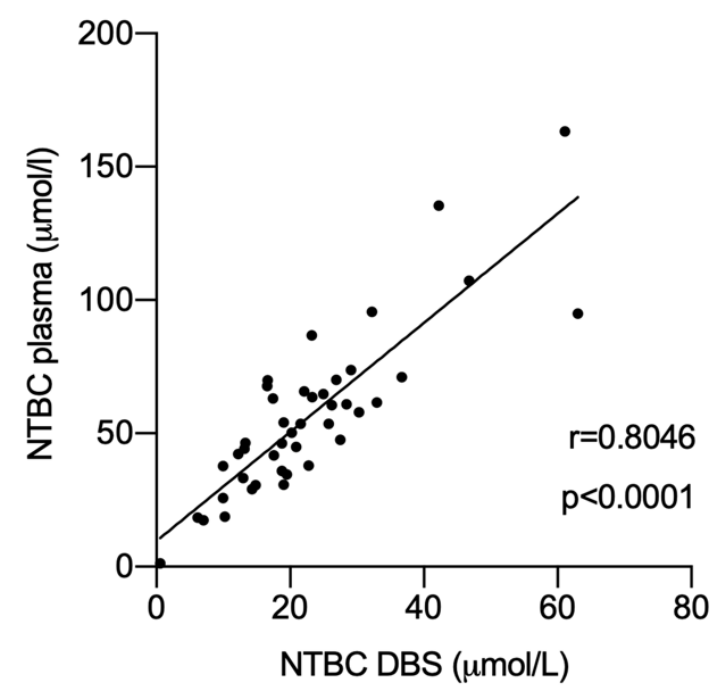

\begin{tabular}{|c|c|c|}
\hline $\begin{array}{c}\text { NTBC DBS } \\
(\mu \mathrm{mol} / \mathrm{L})\end{array}$ & $\begin{array}{c}\text { NTBC plasma } \\
(\mu \mathrm{mol} / \mathrm{L})\end{array}$ & $\begin{array}{c}\text { Plasma/DBS } \\
\text { factor }\end{array}$ \\
\cline { 1 - 2 } $0-14.9$ & $0-38.3$ & \multirow{2}{*}{$2.57 \pm 0.69$} \\
\cline { 1 - 2 } $15-24.9$ & $38.6-64$ & \\
\cline { 1 - 2 } $25-34.9$ & $64.3-89.7$ & \\
\cline { 1 - 2 }$>35$ & $>90$ & \\
\hline
\end{tabular}

Figure 1. Correlation of the NTBC concentration for 43 plasma (umol/L) and DBS ( $\mu \mathrm{mol} / \mathrm{L})$ samples $(r=0.8046 ; p<0.001$; $95 \%$ CI 0.74-0.92). The complement table on the right shows the conversion values for each range with a factor of $2.57 \pm 0.69$. DBS, Dried blood spot.

Table 2. NTBC concentration in plasma and DBS samples at two COVs for succinylacetone levels in urine.

\begin{tabular}{|c|c|c|c|c|c|c|c|c|c|}
\hline & \multirow[b]{2}{*}{$\%$ of Total Samples } & \multicolumn{4}{|c|}{ NTBC DBS } & \multicolumn{4}{|c|}{ NTBC Plasma } \\
\hline & & Mean & $\begin{array}{l}\text { Number of } \\
\text { Samples }\end{array}$ & Median & $\begin{array}{c}p- \\
\text { Value }\end{array}$ & Mean & $\begin{array}{l}\text { Number of } \\
\text { Samples }\end{array}$ & Median & $p$-Value \\
\hline $\begin{array}{c}\text { Samples with } \mathrm{SA}<0.25 \\
\mathrm{mmol} / \mathrm{mol} \text { creatinine }\end{array}$ & 79.5 & 22.9 & 31 & 22.1 & * 0.027 & 57.9 & 31 & 60.5 & $* 0.025$ \\
\hline $\begin{array}{c}\text { Samples with SA }>0.25 \\
\mathrm{mmol} / \mathrm{mol} \text { creatinine }\end{array}$ & 20.5 & 14.4 & 8 & 14.8 & & 35.8 & 8 & 42.1 & \\
\hline $\begin{array}{c}\text { Samples with } \mathrm{SA}<0.5 \\
\mathrm{mmol} / \mathrm{mol} \text { creatinine }\end{array}$ & 89.7 & 23 & 35 & 21.2 & 0.323 & 55.1 & 35 & 53.5 & 0.357 \\
\hline $\begin{array}{l}\text { Samples with SA > } 0.5 \\
\mathrm{mmol} / \mathrm{mol} \text { creatinine }\end{array}$ & 10.3 & 15.5 & 4 & 15.6 & & 38.8 & 4 & 48.2 & \\
\hline
\end{tabular}

${ }^{*} p$-value $<0.05$, according to the Wilcoxon test. NTBC, Nitisinone; DBS, dried blood spot.

\subsection{Determination of Urinary Levels of Succinylacetone and Alpha-Fetoprotein According to NTBC Concentration Range}

Paired samples were sorted by NTBC concentration (in DBS): 0-14.9 $\mu \mathrm{mol} / \mathrm{L}, 15-24.9 \mu \mathrm{mol} / \mathrm{L}$, 25-34.9 $\mathrm{mol} / \mathrm{L}$, and $>35 \mu \mathrm{mol} / \mathrm{L}$. For each range, we determined the mean concentration of $\mathrm{SA}$ in urine and the hepatocarcinogenic biomarker $\alpha \mathrm{FP}$ (Figure 2 and Table 3). Recommended optimal management values for SA and $\alpha \mathrm{FP}$ were identified for the NTBC range in DBS from 15-24.9 $\mu \mathrm{mol} / \mathrm{L}$ (SA below $0.5 \mathrm{mmol} / \mathrm{mol}$ creatinine and $\alpha \mathrm{FP}$ below $10 \mu \mathrm{g} / \mathrm{L}$ ). The mean for SA was $0.2 \mathrm{mmol} / \mathrm{mol}$ creatinine (95\% CI range: $0-0.4$ ) and $8.3 \mu \mathrm{g} / \mathrm{L}$ for $\alpha \mathrm{FP}$ (95\% CI range: $4.8-10.6)$. Levels close to $5 \mu \mathrm{g} / \mathrm{L}$ of $\alpha \mathrm{FP}$ (5.5) were found only at NTBC concentrations higher than $35 \mu \mathrm{mol} / \mathrm{L}$. No significant correlation was found between NTBC and SA or $\alpha \mathrm{FP}$ in the paired-sample comparison. 


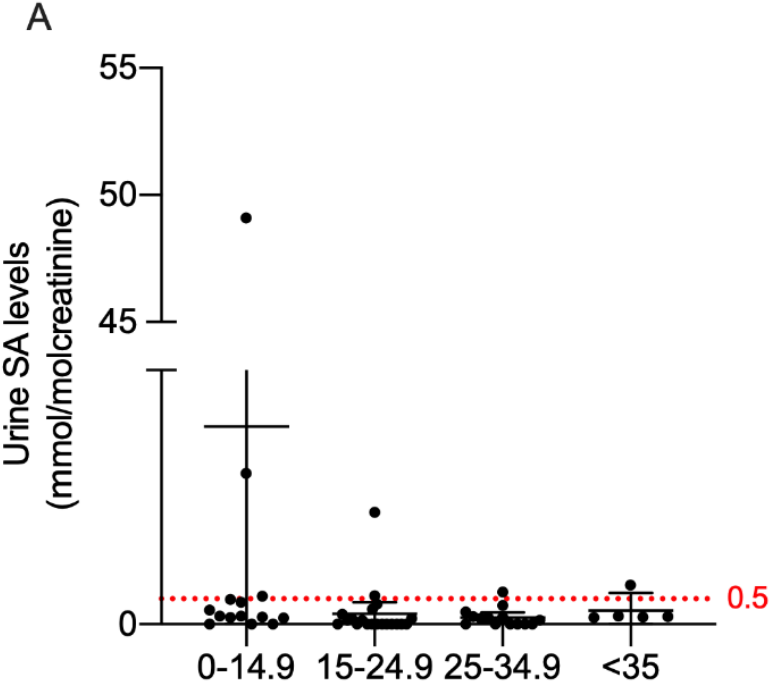

Range of NTBC in DBS ( $\mu \mathrm{mol} / \mathrm{L})$
B

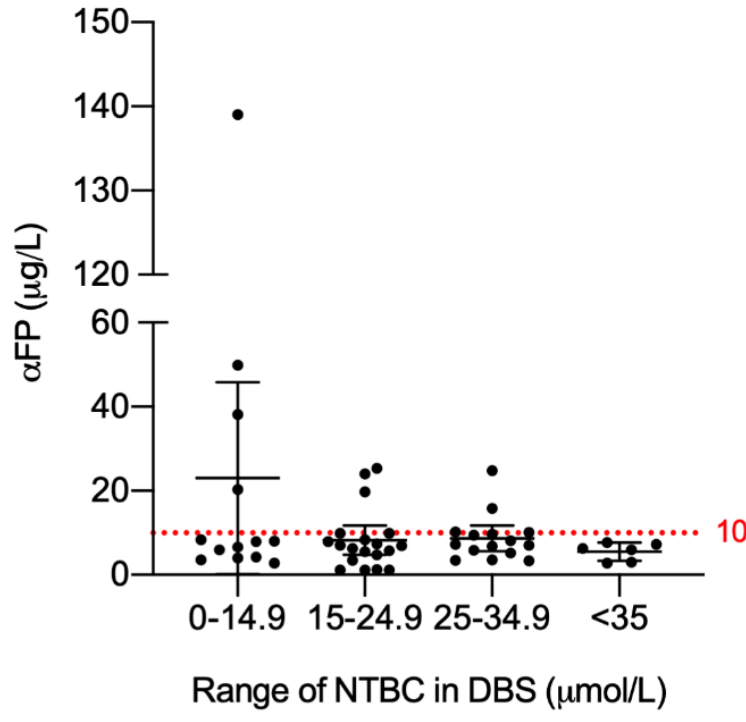

Figure 2. NTBC concentration ranges associated with SA excretion in urine and $\alpha$ FP in plasma. Graph (A): SA; Graph (B): $\alpha \mathrm{FP}$. Dotted lines represent the maximum allowable concentration: $\mathrm{SA}, 0.5 \mathrm{mmol} / \mathrm{mol}$ creatinine in urine; $\alpha \mathrm{FP}, 10 \mu \mathrm{g} / \mathrm{L}$ in plasma. NTBC, Nitisinone; DBS, Dried blood Spot; SA, Succinylacetone; $\alpha$ FP, alpha-fetoprotein.

Table 3. The mean of SA and $\alpha$ FP levels according to the NTBC concentration range in blood samples.

\begin{tabular}{|c|c|c|c|c|}
\hline $\begin{array}{l}\text { Range of NTBC in } \\
\text { DBS }(\mu \mathrm{mol} / \mathrm{L})\end{array}$ & $\begin{array}{c}\text { Number of Paired } \\
\text { Samples }\end{array}$ & $\begin{array}{l}\text { SA in Urine } \\
\text { (mmol/mol } \\
\text { Creatinine) }\end{array}$ & $\begin{array}{c}\text { Number of Paired } \\
\text { Samples }\end{array}$ & $\alpha \mathrm{FP}(\mu \mathrm{g} / \mathrm{L})$ \\
\hline $0-14.9$ & 14 & $\begin{array}{l}\text { Mean } \pm \text { SD: } 3.9 \pm 13.1 \\
\text { CI } 95 \%: 0-11\end{array}$ & 13 & $\begin{array}{l}\text { Mean } \pm \text { SD: } 23 \pm 37.8 \\
\quad \text { CI 95\%: } 0.1-44.5\end{array}$ \\
\hline $15-24.9$ & 19 & $\begin{array}{l}\text { Mean } \pm \text { SD: } 0.2 \pm 0.5 \\
\quad \text { CI } 95 \%: 0-0.41\end{array}$ & 19 & $\begin{array}{l}\text { Mean } \pm \text { SD: } 8.3 \pm 7.2 \\
\quad \text { CI } 95 \%: 3.5-10.6\end{array}$ \\
\hline $25-34.9$ & 14 & $\begin{array}{l}\text { Mean } \pm \text { SD: } 0.1 \pm 0.2 \\
\text { CI 95\%: } 0-0.22\end{array}$ & 15 & $\begin{array}{l}\text { Mean } \pm \text { SD: } 8.7 \pm 5.5 ; \\
\quad \text { CI } 95 \%: 4.8-10.8\end{array}$ \\
\hline$<35$ & 5 & $\begin{array}{l}\text { Mean } \pm \text { SD: } 0.2 \pm 0.3 \\
\quad \text { CI 95\%: } 0-0.46\end{array}$ & 6 & $\begin{array}{c}\text { Mean } \pm \text { SD: } 5.5 \pm 2.1 \\
\text { CI 95\%: } 2.3-6.8\end{array}$ \\
\hline
\end{tabular}

\subsection{Association of Plasma Amino Acids with NTBC Concentration}

We correlated each laboratory monitoring variable with the NTBC concentration in DBS for all samples taken at the four clinical controls in the year of follow-up. No significant correlation was found between NTBC levels and Tyr, Phe, or Phe-Tyr ratios. Interestingly, a significant positive correlation was found when methionine concentrations were analyzed with NTBC level (Spearman $r=0.2963 ; p=0.0239$ ). The Phe-Tyr restricted diet had good adherence in our patients; however, $30 \%$ of analyzed samples registered higher-than-recommended levels. Thus, by segregating NTBC concentrations, as above, we evaluated whether higher NTBC levels significantly influenced amino acid levels in our cohort of patients. Figure 3 shows that the median Tyr levels (Figure 3A) were within the recommended range $(400-600 \mu \mathrm{mol} / \mathrm{L})$ when NTBC concentrations in DBS were up to $34.9 \mu \mathrm{mol} / \mathrm{L}$. However, in samples with higher NTBC levels $(>35 \mu \mathrm{mol} / \mathrm{L})$, elevated Tyr median values outside the acceptable reference range were observed (no statistical difference was found for lower NTBC ranges). In contrast, the Phe concentration remained within optimal values for all the NTBC ranges (Figure 3B). Methionine levels showed an upward trend, which was dependent on NTBC concentration but remained within good metabolic control limits (Figure 3C). 


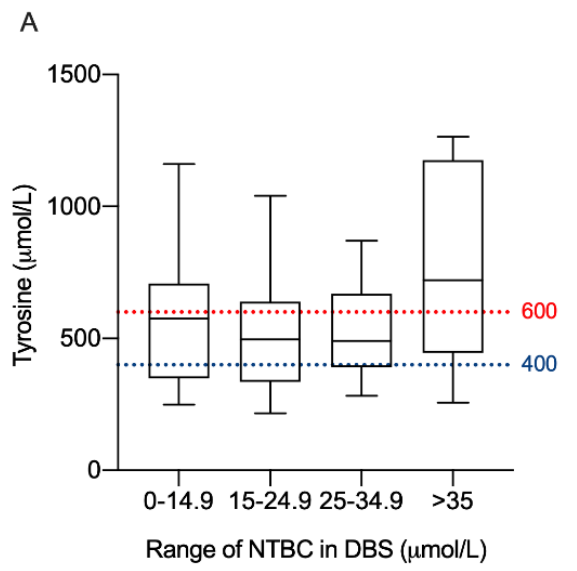

B

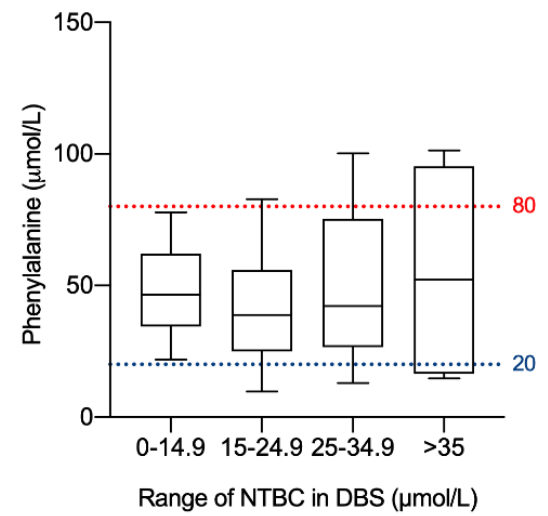

C

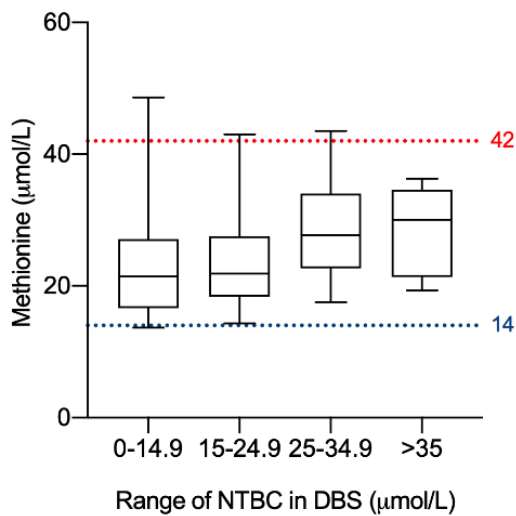

Figure 3. Amino acid variation according to NTBC concentration ranges. Boxplots of Tyr (A); Phe (B); and Met (C) by NTBC concentration ranges. Each boxplot represents the 25th, 50th, and 75th quartiles for each amino acid. Dotted lines represent maximum and minimum allowable concentrations under clinical guidelines: Tyr, 400-600 $\mu \mathrm{mol} / \mathrm{L}$ (for patients $>6$ years old); Phe, 20-80 $\mu \mathrm{mol} / \mathrm{L} ;$ Met, 14-42 $\mu \mathrm{mol} / \mathrm{L}$. Tyr, tyrosine; Phe, phenylalanine; Met, Methionine; DBS, dried blood spot.

\subsection{Association of Liver Biomarkers with NTBC Concentrations}

At clinical appointments, we also monitored liver biomarkers. Table 4 shows the median values for each parameter measured in the study, including coagulation factor (prothrombin time), transaminases (ALT, AST, GGT), direct and total bilirubin, and alkaline phosphatase. Overall, the median values were within the recommended reference values, except for alkaline phosphatase, for which the median value was more than twice the maximum recommended limit, and GGT, for which levels remained outside the normal reference range.

NTBC association with liver biomarkers was addressed through correlation analysis. No significant correlation was found between NTBC concentration in DBS and any liver biomarker listed in Table 4. Liver parameters over one year of follow-up in HT-1 patients did not reveal any significant trends or difference based on NTBC levels segregated by range (Figure S1). Alkaline phosphatase was higher than recommended for all ranges of NTBC concentrations.

Table 4. Liver parameters over one year of follow-up in HT-1 patients.

\begin{tabular}{|c|c|c|c|c|}
\hline & & Values & $\begin{array}{l}\text { Samples Analyzed } \\
(n)\end{array}$ & $\begin{array}{l}\text { Recommended } \\
\text { Reference Value }\end{array}$ \\
\hline \multirow{4}{*}{ Prothrombin time (sec) } & Median & 13.7 & \multirow{4}{*}{48} & \multirow{4}{*}{$11-13.5 \mathrm{sec}$} \\
\hline & Mean \pm SD & $14.6 \pm 4.1$ & & \\
\hline & Min-max & 7.45-31 & & \\
\hline & Median & 1.06 & & \\
\hline \multirow[t]{2}{*}{ INR } & Mean \pm SD & $1.09 \pm 0.12$ & \multirow[t]{3}{*}{48} & \multirow[t]{3}{*}{$0.8-1.1$} \\
\hline & Min-max & $1.0-1.8$ & & \\
\hline \multirow{3}{*}{$\begin{array}{l}\text { Aspartate aminotransferase AST } \\
\text { (UI/L) }\end{array}$} & Median & 35.5 & & \\
\hline & Mean \pm SD & $37.9 \pm 18.5$ & \multirow[t]{2}{*}{52} & \multirow[t]{2}{*}{$15-40 \mathrm{UI} / \mathrm{L}$} \\
\hline & Min-max & $13-103$ & & \\
\hline \multirow{4}{*}{$\begin{array}{c}\text { Alanine aminotransferase ALT } \\
\text { (UI/L) }\end{array}$} & Median & 25 & \multirow{4}{*}{52} & \multirow{4}{*}{ 10-34 UI/L } \\
\hline & Mean \pm SD & $30.2 \pm 23$ & & \\
\hline & Min-max & $10-154$ & & \\
\hline & Median & 0.72 & & \\
\hline \multirow[t]{2}{*}{ ALT/AST } & Mean \pm SD & $0.79 \pm 0.28$ & \multirow[t]{2}{*}{52} & \multirow[t]{2}{*}{1} \\
\hline & Min-max & $0.37-1.56$ & & \\
\hline
\end{tabular}


Table 4. Cont.

\begin{tabular}{|c|c|c|c|c|}
\hline & & Values & Samples Analyzed $(n)$ & $\begin{array}{l}\text { Recommended } \\
\text { Reference Value }\end{array}$ \\
\hline \multirow{3}{*}{ Gamma-glutamyl transferase (GGT) } & Median & 27.5 & \multirow{3}{*}{52} & \multirow{3}{*}{ 11-21 UI/L } \\
\hline & Mean \pm SD & $38 \pm 34$ & & \\
\hline & $\begin{array}{l}\text { Min-max } \\
\text { Median }\end{array}$ & $10-202$ & & \\
\hline \multirow{3}{*}{ Bilirubin direct (mg/dL) } & Mean + SD & $019+024$ & \multirow{3}{*}{48} & \multirow{3}{*}{$0.3(\mathrm{mg} / \mathrm{dL})$} \\
\hline & Min-max & $0.02-1.72$ & & \\
\hline & Median & 0.39 & & \\
\hline \multirow[t]{2}{*}{ Bilirubin total (mg/dL) } & Mean \pm SD & $0.48 \pm 0.31$ & 48 & $0.2-1.2(\mathrm{mg} / \mathrm{dL})$ \\
\hline & Mean + SD & $262+149$ & \multirow{2}{*}{45} & \multirow{2}{*}{$44-147(\mathrm{UI} / \mathrm{L})$ * } \\
\hline Alkaline Phosphatase (UI/L) & Min-max & $\begin{array}{l}202-976 \\
62-976\end{array}$ & & \\
\hline
\end{tabular}

* Age- and gender-dependent range. INR, international normalized ratio; sec, seconds.

\section{Discussion}

During a one-year follow-up period prior to COVID-19 outbreak, we retrospectively observed the overall status of each laboratory parameter and compared them to recommended reference values. Then, we established a conversion factor for NTBC concentration in plasma and DBS samples, allowing us to carry out future NTBC monitoring on DBS, improving the follow-up of HT-1 patients affected by socio-economical and geographical limitations. Finally, we determined the mean values of principal HT- 1 follow-up biomarkers in different ranges of NTBC concentration in blood samples.

In this study, a general analysis of adherence to drug treatment for the period observed revealed that $35 \%$ of the tested samples were within the recommended range for the plasma NTBC concentration [16]; however, when all the samples with values greater than $30 \mu \mathrm{mol} / \mathrm{L}$ were included, the percentage increased to $86 \%$. Plasmatic NTBC concentration above $30 \mu \mathrm{mol} / \mathrm{L}$ has been shown to be sufficient to maintain SA levels below $0.25 \mathrm{mmol} / \mathrm{mol}$ creatinine in urine, as has recently been demonstrated [13]. Eighty percent of patients received an NTBC dose between $0.66-1.2 \mathrm{mg} / \mathrm{kg} /$ day, and two patients ( $>15$ years old) were treated with doses of $0.6 \mathrm{mg} / \mathrm{kg} /$ day, and still presented plasma NTBC values $>30 \mu \mathrm{mol} / \mathrm{L}$ with SA excretion values below $0.5 \mathrm{mmol} / \mathrm{mol}$ creatinine. Pharmacological treatment is administered as two doses/day, which may explain the optimal concentration of NTBC in plasma, which has been shown to be beneficial in maintaining stable NTBC levels in the blood and effectively preventing an increase in SA $[10,14,20]$. However, this may negatively impact adherence to treatment, leading to poorer metabolic control [21,22]. In our analysis, we found that $70 \%$ of HT-1 patients presented with adequate nutritional adherence, achieved by a controlled diet restricted in Phe/Tyr. We are aware that more in-depth and long-term studies are needed in order to better describe dietary and pharmacological adherence in this cohort.

Upon measuring the NTBC concentration in plasma and DBS samples, we found a slight difference in the conversion factor (cf) calculated for NTBC concentrations in plasma and DBS, compared to the inter-laboratory studies carried out by Laeremans [17] $(\mathrm{cf}=2.4)$ and the Spanish group $(\mathrm{cf}=2.34)$ [18]. Our determination was slightly higher $(2.57)$ and consistent with our initial reports in 2019 [19]. The ethnicity of our population, the wide age range ( 1 year, 3 months to 23 years, 4 months), and the age-dependent hematocrit value could explain the difference between our findings and those of the European cohorts. It is important to note that our LC-MSMS method for the NTBC quantification was first validated by measuring NTBC levels in DBS samples from Chilean HT-1 patients in parallel with the U.K. Center at Evelina Children's Hospital [19].

The SA level in HT-1 patients should be managed below the limits of detection or within limits established by each laboratory $[17,23,24]$, which is dependent on instrument sensitivity [17]. We established a first COV for urine SA monitoring of $0.5 \mathrm{mmol} / \mathrm{mol}$ creatinine. For this COV, $89 \%$ of samples presented levels below $0.5 \mathrm{mmol} / \mathrm{mol}$ creatinine. Interestingly, when a lower COV was used $(0.25 \mathrm{mmol} / \mathrm{mol}$ creatinine), no significant difference in median NTBC levels was observed regarding to COV $0.5 \mathrm{mmol} / \mathrm{mol} \mathrm{crea-}$ 
tinine. These results suggest no major difference in NTBC concentrations for a COV of less than $0.5 \mathrm{mmol} / \mathrm{mol}$ creatinine for SA. On the other hand, monitoring of SA in DBS has been strongly encouraged and validated in the past few years [11,14]. In a recently published study, the average NTBC concentration in blood in paired samples with SA levels $<0.3 \mu \mathrm{mol} / \mathrm{L}$ in DBS was $17.2 \mu \mathrm{mol} / \mathrm{L}$ [14], lower than the mean value found in our study $(21.2 \mu \mathrm{mol} / \mathrm{L})$, which considered a COV of SA in urine of $0.5 \mathrm{mmol} / \mathrm{mol}$ creatinine. These differences can be explained by the sensitivity of the method, daily variation of SA levels, the stability of the matrix, and other factors. Future comparative studies of SA stability and simultaneous determination of its concentration in plasma, blood, and urine are required. Despite such differences, our findings are consistent with Yeo [14] and Shultz's [11] observations that target NTBC levels in the blood could be lower than currently recommended. Nonetheless, this primary finding should be considered carefully, and in light of the limitations of our study, further prospective studies with a greater number of samples and longer observational times are encouraged to be performed in the future. Additionally, standardized SA measurement in blood samples will allow us to unify criteria and contribute to evaluating future clinical recommendations regarding to the values of blood NTBC for therapy monitoring.

Periodic evaluation of other liver biomarkers has been proposed as essential for closely monitoring the outcome of hepatic complications [7]. Although no significant differences could be found between the association of NTBC levels with SA levels in urine and $\alpha \mathrm{FP}-$ the primary marker for HCC - we observed a negative association trend. Moreover, with a $95 \%$ confidence interval, we observed that, above the range of $15-24.9 \mu \mathrm{mol} / \mathrm{L}$ of NTBC in DBS, SA levels and $\alpha$ FP fell within the recommended monitoring parameters [16,25-27]. Although a COV of $10 \mu \mathrm{g} / \mathrm{L}$ for $\alpha \mathrm{FP}$ has been established in several reviews and consensus guidelines [28], subtle elevation within this range might indicate a progression in liver damage, especially in clinically diagnosed patients. No other robust biomarkers have yet been found to support $\alpha \mathrm{FP}$ in predicting the risk of carcinogenesis. An example of this is a patient included in this study with late diagnosis (12 months) who developed, during the observed period, an abrupt elevation of $\alpha \mathrm{FP}$ (from $7.3 \mu \mathrm{g} / \mathrm{L}$ to $2470 \mu \mathrm{g} / \mathrm{L}$ within 3 months), concomitant with evidence of suppressed levels of SA $(<0.2 \mathrm{mmol} / \mathrm{mol}$ creatinine). This illustrates the need to search for better biomarkers to predict prognosis, particularly considering that patients with late diagnosis, such as ours, will probably have greater liver complications during their lifetimes $[12,22,28]$.

Beyond the $\alpha \mathrm{FP}$ analyzed herein, no major associations between transaminase levels, coagulation measurements, or bilirubin and NTBC concentrations could be found. However, some parameters of liver function, such as alkaline phosphatase and GGT, were elevated in relation to our laboratory's normal reference range. It has been reported that NTBC slightly elevates transaminase values [29], which was supported by our observations. The association analysis of NTBC with liver biomarkers in a heterogeneous cohort of HT-1 patients that included a majority of patients with more than 5 years of NTBC treatment (13 from 15 patients) suggested no greater variability on biomarkers levels related to NTBC blood concentration in this one-year observational study. In-depth studies are required to clarify the exact impact of other variables on chronic liver damage in patients with late diagnoses, such as long-term exposure to NTBC.

We did not find any significant association of NTBC with Tyr and Phe, unlike that which has been recently reported by Gonzalez-Lamuño [30], who found a positive correlation with Tyr levels and the Phe/Tyr ratio. This difference can be explained by the poor dietary adherence of Spanish HT- 1 patients, where $54 \%-64.4 \%$ of patients exceeded recommended Tyr levels. In contrast to the Spanish cohort, we found $70 \%$ adherence to dietary treatment, and Tyr levels tended to be outside acceptable management values only at the highest range of NTBC concentrations $(>35 \mu \mathrm{mol} / \mathrm{L})$. On the other hand, methionine was positively correlated with NTBC, but the levels were within acceptable follow-up ranges even at high concentrations of NTBC. The role of methionine in chronic liver disease 
has recently been reviewed by Li, Z. et al. [31] and warrants consideration as an indicator of progressive liver dysfunction in HT-1.

\section{Conclusions}

This is the first study carried out in Chile that has attempted to associate NTBC levels with biochemical parameters in HT-1 patients who are part of the 24-year-old follow-up tyrosinemia program. Our results revealed that our cohort of HT-1 patients presented acceptable overall compliance with NTBC and dietary treatment, despite diversity in age, time exposure to NTBC, and clinical onset. Additionally, we demonstrated that measurement of NTBC in DBS is well correlated with NTBC plasma levels, enabling us include them in laboratory monitoring in the follow-up program. Data extracted from a series of HT-1 patients with a clinical diagnosis (not by neonatal screening) with longterm follow-up not only reaffirmed the evidence obtained in countries that have high economic resources, but also suggests the utility of medium- and low-income countries to engage in follow-up of their patients according to international guidelines and publish their experiences, beyond the difficulties they may have in achieving adequate diagnosis and treatment for their patients.

Supplementary Materials: The following are available online at https:/ /www.mdpi.com/article/10 .3390/jcm10245832/s1, Figure S1: Liver biomarkers in association with NTBC plasma concentration.

Author Contributions: K.F. and M.J.L.-W. equally contributed to the research conceptualization and preparation of the manuscript. Conceptualization, K.F. and M.J.L.-W.; methodology P.G.; data acquisition and validation, P.G., M.J.L.-W., V.H., M.F.S., F.P. and C.A.; formal analysis, K.F. and M.J.L.W.; investigation, K.F. and M.J.L.-W.; writing—original draft preparation, K.F.; writing-review and editing, M.J.L.-W., V.C. and C.A.; supervision, V.C.; funding acquisition, V.C. All authors have read and agreed to the published version of the manuscript.

Funding: This research was funded by Corporacion de apoyo a la Investigación en Nutrición, CINUT.

Institutional Review Board Statement: The study was conducted according to the guidelines of the Declaration of Helsinki and approved by the Ethics Committee of Institute of Nutrition and Food Technology (protocol act no. 18, project no. 28, year 2021; approved on 26 May 2021).

Informed Consent Statement: Informed consent was obtained from all subjects involved in the study.

Data Availability Statement: The data can be obtained by contacting the first author, K.F.

Acknowledgments: The authors would like to acknowledge all the patients and their families that participated in this study, as well as the medical, nutritionist, and laboratory staff of the LabGEM of INTA, University of Chile, and Calvo Mackenna Children's Hospital in Santiago de Chile, for their assistance. We also thank Cristiano Rizzo from the Metabolic Biochemistry Laboratory of Bambino Gesú Children's Hospital in Rome for his kind support with LC-MSMS implementation methods.

Conflicts of Interest: The authors declare no conflict of interest.

\section{References}

1. Cycle Pharmaceuticals Ltd. Clinical Review Report: Nitisinone (Nitisinone Tablets). In Indication: For the Treatment of Patients with Hereditary Tyrosinemia Type 1 in Combination with Dietary Restriction of Tyrosine and Phenylalanine; Canadian Agency for Drugs and Technologies in Health: Ottawa, ON, Canada, 2018. Available online: http:/ / www.ncbi.nlm.nih.gov/books/NBK539976/ (accessed on 10 September 2021).

2. Angileri, F.; Bergeron, A.; Morrow, G.; Lettre, F.; Gray, G.; Hutchin, T.; Ball, S.; Tanguay, R.M. Geographical and Ethnic Distribution of Mutations of the Fumarylacetoacetate Hydrolase Gene in Hereditary Tyrosinemia Type 1. In JIMD Reports Volume 19; Zschocke, J., Baumgartner, M., Morava, E., Patterson, M., Rahman, S., Peters, V., Eds.; Springer: Berlin/Heidelberg, Germany, 2015; pp. 43-58. [CrossRef]

3. Morrow, G.; Tanguay, R.M. Biochemical and Clinical Aspects of Hereditary Tyrosinemia Type 1. In Hereditary Tyrosinemia; Tanguay, R.M., Ed.; Springer International Publishing: Cham, Switzerland, 2017; pp. 9-21. [CrossRef]

4. Couce, M.L.; Dalmau, J.; del Toro, M.; Pintos-Morell, G.; Aldámiz-Echevarría, L.; Spanish Working Group on Tyrosinemia Type 1. Tyrosinemia type 1 in Spain: Mutational analysis, treatment and long-term outcome: Tyrosinemia type 1 in Spain. Pediatr. Int. 2011, 53, 985-989. [CrossRef] 
5. Holme, E.; Lindstedt, S. Tyrosinaemia type I and NTBC (2-(2-nitro-4-trifluoromethylbenzoyl)-1,3-cyclohexanedione). J. Inherit. Metab. Dis. 1998, 21, 507-517. [CrossRef] [PubMed]

6. $\quad$ Larochelle, J.; Alvarez, F.; Bussières, J.F.; Chevalier, I.; Dallaire, L.; Dubois, J.; Faucher, F.; Fenyves, D.; Goodyer, P.; Grenier, A.; et al. Effect of nitisinone (NTBC) treatment on the clinical course of hepatorenal tyrosinemia in Québec. Mol. Genet. Metab. 2012, 107, 49-54. [CrossRef] [PubMed]

7. van Ginkel, W.G.; Rodenburg, I.L.; Harding, C.O.; Hollak, C.E.M.; Heiner-Fokkema, M.R.; van Spronsen, F.J. Long-Term Outcomes and Practical Considerations in the Pharmacological Management of Tyrosinemia Type 1. Pediatr. Drugs 2019, 21, 413-426. [CrossRef]

8. van Ginkel, W.G.; Gouw, A.S.H.; van der Jagt, E.J.; de Jong, K.P.; Verkade, H.J.; van Spronsen, F.J. Hepatocellular carcinoma in tyrosinemia type 1 without clear increase of AFP. Pediatrics 2015, 135, e749-e752. [CrossRef]

9. van Spronsen, F.J.; van Rijn, M.; Meyer, U.; Das, A.M. Dietary Considerations in Tyrosinemia Type, I. Adv. Exp. Med. Biol. 2017, 959, 197-204. [CrossRef] [PubMed]

10. Kienstra, N.S.; van Reemst, H.E.; van Ginkel, W.G.; Daly, A.; van Dam, E.; MacDonald, A.; Burgerhof, J.G.; de Blaauw, P.; McKiernan, P.J.; Heiner-Fokkema, M.R.; et al. Daily variation of NTBC and its relation to succinylacetone in tyrosinemia type 1 patients comparing a single dose to two doses a day. J. Inherit. Metab. Dis. 2018, 41, 181-186. [CrossRef]

11. Schultz, M.J.; Netzel, B.C.; Singh, R.H.; Pino, G.B.; Gavrilov, D.K.; Oglesbee, D.; Raymond, K.M.; Rinaldo, P.; Tortorelli, S.; Smith, W.E.; et al. Laboratory monitoring of patients with hereditary tyrosinemia type I. Mol. Genet. Metab. 2020, 130, 247-254. [CrossRef] [PubMed]

12. Mayorandan, S.; Meyer, U.; Gokcay, G.; Segarra, N.G.; De Baulny, H.O.; Van Spronsen, F.; Zeman, J.; De Laet, C.; Spiekerkoetter, U.; Thimm, E.; et al. Cross-sectional study of 168 patients with hepatorenal tyrosinaemia and implications for clinical practice. Orphanet J. Rare Dis. 2014, 9, 107. [CrossRef]

13. Jack, R.M.; Scott, C.R. Validation of a therapeutic range for nitisinone in patients treated for tyrosinemia type 1 based on reduction of succinylacetone excretion. JIMD Rep. 2019, 46, 75-78. [CrossRef]

14. Yeo, M.; Turner, C.; Dalton, N.R.; Rahman, Y.; Vara, R. Clinical utilization of dried blood spot nitisinone (NTBC) and succinylacetone (SA) concentrations in hereditary tyrosinaemia type 1-A UK centre experience. Ann. Clin. Biochem. Int. J. Lab. Med. 2020, 57, 412-419. [CrossRef]

15. Public Health Division, Ministery of Health, Chile. Clinical Management of Tyrosinemia. Available online: https://www.minsal. cl/wp-content/uploads/2015/08/Orientaciones-Tirosinemia-rev-15122015.pdf (accessed on 10 September 2021).

16. Chinsky, J.M.; Singh, R.; Ficicioglu, C.; Van Karnebeek, C.D.; Grompe, M.; Mitchell, G.; Waisbren, S.E.; Gucsavas-Calikoglu, M.; Wasserstein, M.P.; Coakley, K.; et al. Diagnosis and treatment of tyrosinemia type I: A US and Canadian consensus group review and recommendations. Genet. Med. 2017, 19, 1380. [CrossRef]

17. Laeremans, H.; Turner, C.; Andersson, T.; de Juan, J.A.C.; Gerrard, A.; Heiner-Fokkema, M.R.; Herebian, D.; Janzen, N.; La Marca, G.; Rudebeck, M. Inter-laboratory analytical improvement of succinylacetone and nitisinone quantification from dried blood spot samples. JIMD Rep. 2020, 53, 90-102. [CrossRef]

18. Prieto, J.A.; Andrade, F.; Lage, S.; Aldámiz-Echevarría, L. Comparison of plasma and dry blood spots as samples for the determination of nitisinone (NTBC) by high-performance liquid chromatography-tandem mass spectrometry. Study of the stability of the samples at different temperatures. J. Chromatogr. B 2011, 879, 671-676. [CrossRef] [PubMed]

19. Wiley, V.; Webster, D.; Loeber, G. Screening Pathways through China, the Asia Pacific Region, the World. Int. J. Neonatal Screen. 2019, 5, 26. [CrossRef]

20. Sander, J.; Janzen, N.; Terhardt, M.; Sander, S.; Gökcay, G.; Demirkol, M.; Ozer, I.; Peter, M.; Das, A.M. Monitoring tyrosinaemia type I: Blood spot test for nitisinone (NTBC). Clin. Chim. Acta 2011, 412, 134-138. [CrossRef] [PubMed]

21. Schlune, A.; Thimm, E.; Herebian, D.; Spiekerkoetter, U. Single dose NTBC-treatment of hereditary tyrosinemia type I. J. Inherit. Metab. Dis. 2012, 35, 831-836. [CrossRef] [PubMed]

22. Das, A. Clinical utility of nitisinone for the treatment of hereditary tyrosinemia type-1 (HT-1). Appl. Clin. Genet. 2017, 10, 43-48. [CrossRef]

23. Herebian, D.; Spiekerkötter, U.; Lamshöft, M.; Thimm, E.; Laryea, M.; Mayatepek, E. Liquid chromatography tandem mass spectrometry method for the quantitation of NTBC (2-(nitro-4-trifluoromethylbenzoyl)1,3-cyclohexanedione) in plasma of tyrosinemia type 1 patients. J. Chromatogr. B 2009, 877, 1453-1459. [CrossRef]

24. La Marca, G.; Malvagia, S.; Materazzi, S.; Della Bona, M.L.; Boenzi, S.; Martinelli, D.; Dionisi-Vici, C. LC-MS/MS Method for Simultaneous Determination on a Dried Blood Spot of Multiple Analytes Relevant for Treatment Monitoring in Patients with Tyrosinemia Type, I. Anal. Chem. 2012, 84, 1184-1188. [CrossRef]

25. De Laet, C.; Dionisi-Vici, C.; Leonard, J.V.; McKiernan, P.; Mitchell, G.; Monti, L.; De Baulny, H.O.; Pintos-Morell, G.; Spiekerkötter, U. Recommendations for the management of tyrosinaemia type 1. Orphanet J. Rare Dis. 2013, 8, 8. [CrossRef] [PubMed]

26. El-Karaksy, H.; Rashed, M.; El-Sayed, R.; El-Raziky, M.; El-Koofy, N.; El-Hawary, M.; Al-Dirbashi, O. Clinical practice: NTBC therapy for tyrosinemia type 1: How much is enough? Eur. J. Pediatr. 2010, 169, 689-693. [CrossRef]

27. Koelink, C.J.L.; van Hasselt, P.; van der Ploeg, A.; Van den Heuvel-Eibrink, M.M.; Wijburg, F.A.; Bijleveld, C.M.A.; Van Spronsen, F.J. Tyrosinemia type I treated by NTBC: How does AFP predict liver cancer? Mol. Genet. Metab. 2006, 89, 310-315. [CrossRef]

28. Zeybek, C.A.; Zubarioglu, T. Nitisinone: A review. Orphan Drugs Res. Rev. 2017, 7, 25-35. [CrossRef] 
29. Introne, W.J.; Perry, M.B.; Troendle, J.; Tsilou, E.; Kayser, M.A.; Suwannarat, P.; O’Brien, K.E.; Bryant, J.; Sachdev, V.; Reynolds, J.C.; et al. A 3-year randomized therapeutic trial of nitisinone in alkaptonuria. Mol. Genet. Metab. 2011, 103, 307-314. [CrossRef] [PubMed]

30. González-Lamuño, D.; Sánchez-Pintos, P.; Andrade, F.; Couce, M.L.; Aldámiz-Echevarría, L. Treatment adherence in tyrosinemia type 1 patients. Orphanet J. Rare Dis. 2021, 16, 256. [CrossRef] [PubMed]

31. Li, Z.; Wang, F.; Liang, B.; Su, Y.; Sun, S.; Xia, S.; Shao, J.; Zhang, Z.; Hong, M.; Zhang, F.; et al. Methionine metabolism in chronic liver diseases: An update on molecular mechanism and therapeutic implication. Signal Transduct. Target. Ther. 2020, 5, 280. [CrossRef] [PubMed] 